BULLETIN Bulletin hispanique

HISPANIQUE Université Michel de Montaigne Bordeaux

114-2 | 2012

Varia

\title{
Del ángel y el animal en la poesía de Blanca Varela
}

Ina Salazar

\section{OpenEdition}

Journals

Édition électronique

URL : https://journals.openedition.org/bulletinhispanique/1397

DOI : 10.4000/bulletinhispanique.1397

ISSN : 1775-3821

\section{Éditeur}

Presses universitaires de Bordeaux

\section{Édition imprimée}

Date de publication : 31 décembre 2012

Pagination : $671-701$

ISBN : 978-2-86781-855-4

ISSN : 0007-4640

Référence électronique

Ina Salazar, « Del ángel y el animal en la poesía de Blanca Varela », Bulletin hispanique [En ligne], 114-2 | 2012, mis en ligne le 05 janvier 2016, consulté le 28 juillet 2022. URL : http://journals.openedition.org/ bulletinhispanique/1397 ; DOI : https://doi.org/10.4000/bulletinhispanique.1397 


\title{
Del ángel y el animal en la poesía de Blanca Varela
}

\author{
INA SALAZAR \\ Université de Caen-Basse Normandie
}

"Del ángel y el animal en la poesía de Blanca Varela" propose une analyse des différentes valeurs et fonctions adoptées, dans l'ouvre de la poète péruvienne, par les figures de l'ange et de l'animal. Ceux-ci se présentent comme deux manifestations antithétiques qui servent la même intention, celle de représenter une altérité depuis laquelle l'humain est regardé et approché.

Mots-clés: poésie péruvienne contemporaine, Blanca Varela, ange, animal, altérité, sacré, humanité, finitude, sujet.

"Del ángel y el animal en la poesía de Blanca Varela» examina los diferentes valores y funciones que asumen en la obra de la peruana las representaciones del ángel y del animal. Estos aparecen como dos manifestaciones que, desde extremos opuestos, sirven una misma intención, la de la figuración de una otredad desde la que se mira y se explora lo humano.

Palabras claves: poesía peruana contemporánea, Blanca Varela, ángel, animal, alteridad, sagrado, humanidad, finitud, sujeto.

"The Angel and the Animal in the poetry of Blanca Varela" proposes an analysis of the different values and functions that these two figures adopt in the work of the Peruvian poet. They appear as two opposite poles that serve the same purpose: feature a possible otherness that observes and captures the human being.

Keywords: contemporary Peruvian poetry, Varela (Blanca), angel, animal, otherness, the sacred, humanity, finitude, subject.

$\mathrm{B}$ lanca Varela (Lima, 1925-2008), constituye una de las voces más singulares de la poesía hispanoamericana del siglo $\mathrm{XX}$, no sólo porque se deja oír como algunas otras poetas mujeres, la argentina Olga Orozco o las uruguayas Idea Vilariño e Ida Vitale, dentro del concierto más bien masculino que ocupa el espacio poético hasta los 70-80, sino también y sobre todo porque 
su palabra afirma con vigor, al margen de las escuelas y de las modas, la vitalidad de una tradición poética peruana que, desde Vallejo y Eguren hasta nuestros días, muestra una permanente renovación de sus medios expresivos. Su obra, si se piensa en la larga vida de la poeta, es relativamente breve o más bien concisa. Los ocho poemarios que la conforman, Este puerto existe (1959), Luz de día (1963), Valses y otras falsas confesiones (1971), Canto villano (1978), Ejercicios materiales (1993), El libro de barro (1994), Concierto animal (1999), El falso teclado (2000), revelan un verbo que se presenta siempre esencial, medular, despojado, arisco a todo lo superfluo y que convive de manera permanente con el silencio. En ese sentido, la brevedad o "cortedad» de su decir expresa un deseo de contención, traduce lentos, necesarios procesos de maduración que se materializan en la distancia y el tiempo que separan a menudo un poemario de otro ${ }^{1}$. Los libros que construyen su itinerario poético se presentan como las diferentes y necesarias etapas o más bien las estancias (los lugares) ${ }^{2}$ en que se despliega, más que la paulatina constitución de una lengua propia, una aventura antes que nada interior, la búsqueda del «sitio del alma» («.../y todo debe ser mentira/porque no estoy en el sitio de mi alma/...») $)^{3}$, como lo observa Adolfo Castañón, aventura que se asemeja en ciertos aspectos a la aventura mística, pero que se define fundamentalmente como un careo constante del yo con el mundo y consigo misma. Inscribiéndose no al margen de la Historia, sino en su envés, de todas maneras a contracorriente de las prácticas más en boga que le son contemporáneas en América Latina, como la poesía social y luego la conversacional, la obra de Blanca Varela nunca dice frontalmente su circunstancia, sino que escruta cómo el sujeto, "la" sujeto está en ella, interrogando justamente, en un imposible vaivén, las fronteras entre interior y exterior, efectuando diversos y continuos asedios para auscultar nuestra plural e imperfecta naturaleza humana.

Su singularidad, sin embargo, como lo ha observado con frecuencia la crítica, le debe algo al surrealismo, cuyo influjo fue tan poderoso en América Latina durante la primera mitad el siglo XX. En el caso preciso de Varela, fue un legado trasmitido en gran parte por los poetas peruanos César Moro y Emilio Adolfo Westphalen, maestros en la integridad y en la corrosión.

1. Salvo el caso de Ejercicios materiales y El libro de barro, escritos según la autora casi simultáneamente.

2. Algo del sentido que María Zambrano le otorga a la noción de lugar, inspirándose en Aristóteles : "Contribuye grandemente a que la antigua categoría de "lugar" no sea tenida en cuenta por aquellos que no la desechan sin más por su inconfundible sello aristotélico el que, tratándose de sucesos y seres vivientes, el lugar no sea algo fijo. Bien es verdad que, a lo que sabemos en el pensamiento aristotélico el lugar se aplica, como el lugar natural de las cosas de la naturaleza, no [a] las del humano hacer de la historia, a esa historia que envuelve a todo lo que el hombre hace, aunque sea en unión de algo, como la inspiración, la oportunidad o el mismo azar, que el hombre no maneja y que por momentos parecen manejarle», en María Zambrano, Algunos lugares de la poesía. Madrid, Editorial Trotta, 2007, p. 47.

3. En "Conversación con Simone Weil», (de Valses y otras falsas confesiones), Donde todo termina abre las alas, Poesía reunida (1949-2000), Barcelona, Galaxia Gutemberg-Círculo de Lectores, 2001, p. 121. Esta será la edición de referencia a lo largo de mi trabajo. 
También fueron esenciales en su formación, aunque de ello se ha hablado menos, las lecciones recibidas por el existencialismo, la experiencia directa de la posguerra europea, en los ańos primordiales de su juventud, pasados en París 4 . La propia autora afirma, incluso, en varias entrevistas, sentirse pertenecer "como generación tal vez más al existencialismo que al surrealismo»" y haber sido marcada por el contacto con gente como Sartre y Beauvoir, a los que frecuentó ${ }^{6}$. Son esos ańos europeos los que signan su entrada en poesía y le permiten tomar conciencia de pertenecer a una generación de creadores a la que no le tocó sino re-conocer, explorar esos tiempos modernos, nada felices, carentes de perspectivas e ilusiones que se presentaban, según la justa y definitiva imagen de Octavio Paz, como un largo túnel. Los poetas de la generación de Blanca Varela no pudieron sino re-conocerlos, explorarlos "como se explora un continente desierto, una enfermedad, una prisión" ${ }^{7}$. La autora peruana se inicia poéticamente en la desazón de esa Europa que tocó el punto límite, lo impensable (humano), esas «lecciones» que el hombre dio al infierno, según André Malraux, después de lo cual el sentido de la palabra se veía comprometido (según la sentencia de Adorno), corría el riesgo de no ser sino «residuo cantable», "palabra que balbucea o tiende a enmudecer», como lo demostró la poesía de Paul Celan, con un verbo enfermo «en un mundo sin nada más, sin nadie que aporte autoridad - menos aún, que "garantice" la menor relación con el otro, cualquiera (o quienquiera) que sea- que aporte el menor diálogo» ${ }^{8}$. Ese mundo, abandonado a sí mismo, en que la desmiraculización, la ausencia de Dios, de los dioses adquiría otro sentido, una nueva dimensión ante la soberbia humana, exacerbando el sentimiento de orfandad, de vacío de trascendencia, Varela lo presencia, lo vive y repercute en su poesía. Además de la singularidad de cada voz, de toda voz, Blanca Varela como peruana y latinoamericana participa de esta realidad histórico-cultural occidental desde una vera a otra, descentrada, periférica, que tiene además sus propios hitos y tensiones, que sigue su propia dinámica (en particular, a partir de fines de los cincuenta, con respecto a las expectativas suscitadas por la revolucion cubana y los condicionamientos de la poesía comprometida, social). Ese presente que es tierra baldía o largo túnel no va a ser proferido, escrito necesariamente desde una palabra desfalleciente o culpable; Blanca Varela recuerda en una de sus entrevistas que los artistas, los poetas si en algo creían era «en la literatura,

4. Blanca Varela y Fernando de Szsyslo, recién casados, hicieron un primer viaje a Europa en 1949. Vuelven a Lima en 1951, Blanca Varela regresa sola a París en 1953, es entonces cuando entabla amistad con Jean-Paul Sartre y Simone de Beauvoir, Claude y Jacques Lanzmann, Alberto Giacometti. En 1954, vive en Florencia; regresa a Lima en 1955 con Szsyslo.

5. Edgar O’Hara, «El recuerdo del recuerdo-conversación con Blanca Varela», Revista Peruana de Cultura 2, 1984, p. 14-15.

6. Roland Forgues, Palabra Viva: las poetas se desnudan. Lima, El Quijote, 1991, p. 80.

7. En su prólogo del primer poemario de Blanca Varela, Ese puerto existe, Veracruz, Universidad Veracruzana, p. 15.

8. Philippe Lacoue-Labarthe, La poésie comme expérience, consultado en su traducción española, La poesía como experiencia, Madrid, Arena Libros, 2006, p. 41. 
en el arte, creían en el sueño, en el poema, en el canto» ${ }^{9}$; Paz habla de una fe en el poder del signo, habla de exorcismos y conjuros, de la poesía como un acto de legítima defensa. Se trata de una poesía que paradójicamente afirma su vitalidad en la exploración, el reconocimiento de una realidad, de un mundo (percibidos como) profundamente insatisfactorios, de una modernidad que no ofrece mayores perspectivas, sin horizontes. Es una exploración que tiene como correlato necesario la exploración de la propia conciencia y de sus límites, «se trata -como dice la poeta- de darles nombre a todas las sombras, a todos los fantasmas de ese túnel; de domesticarlos con la palabra o con el canto, de confundirnos con ellos, de ser ellos, de asumirlos» ${ }^{10}$. El escrutamiento de la existencia se lleva a cabo desde la conciencia de sus límites, es decir, entre otras cosas, de la ausencia de toda trascendencia - no hay Dios, no hay cielo, no hay sagrado que nos ampare ni envuelva- y es, en ese sentido, una escritura que intenta situarse en una existencia, un mundo al que hemos sido arrojados, y del cual no podemos escapar. La poesía de Blanca Varela recrea el tiempo finito humano a través de un mismo gesto que parece repetirse, que se renueva, que vuelve incesante a los mismos lugares, a los mismos estados o situaciones, podríamos decir con Roberto Paoli y Adolfo Castañón a la manera de un Sísifo moderno $^{11}$.

Desde Ese puerto existe, libro inaugural, en que se va conformando el yo en tanto que sujeto que enuncia y experimenta, hasta el poemario final, El falso teclado, en que se intenta proferir la cercana muerte, se traza, en la escritura de la peruana, una línea que se va tensando, densificando. El «acoso de la realidad» como ella misma lo define ${ }^{12}$, que lleva a cabo y se centra en la captación del vivir en su ambigüedad más concreta e inmediata, plantea en cada libro ciertas exigencias y va construyendo un determinado horizonte ético («Después con el tiempo la poesía para mí ya no ha sido hacer poesía; ha sido una manera de vivir») ${ }^{13}$. Se trata de la búsqueda de una autenticidad imposible y una manera de estar en el mundo, llevada a cabo por un(a) sujeto que se impone a sí misma ciertas normas. Estas cristalizan en la escritura, a lo largo de los diferentes

9. «La realidad es ingrata, era ingrata para todos en ese momento, para toda una generación ... Además somos gentes que no teníamos otra fe que la literatura porque políticamente si bien éramos sumamente sensibles a ... no quiero citar la palabra izquierda porque en un sentido esa palabra está desprestigiada ... éramos sumamente radicales, preocupados por los cambios. Pero no teníamos un riel, un tren o esa cosa que te da tener un partido político o una religión ... Creíamos en el sueño. en el poema. en el canto» (Edgar O'Hara, op. cit. p. 15).

10. Blanca Varela, «Antes de escribir estas líneas», Cuadernos Hispanoamericanos 417, 1985, p. 84.

11. Roberto Paoli, «Una visión lúcida y desencantada», en Mariella Dreyfus, Rocío Silva Santisteban (ed.), Nadie sabe mis cosas: reflexiones en torno a la poesía de Blanca Varela, Lima, Fondo Editorial del Congreso del Perú, 2006; Adolfo Castañón, «Blanca Varela: La poesía como una conquista del silencio", en Donde todo termina abre las alas, poesía reunida (1949-2000), op. cit.

12. En "Antes de escribir estas líneas.», op. cit., p. 84.

13. En Roland Forgues, op. cit. p. 84. 
poemarios, en un incesante frotamiento y tensión entre poesía y verdad. En ese sentido, en Luz de día se gesta una conciencia lúcida, en Valses y otras falsas confesiones el concepto y valor de la autenticidad se miden en la tensión con la confesión y el sentimiento, en Canto Villano y, sobre todo, en Ejercicios Materiales, más radicalmente aún, la exploración va a buscar los límites, hacer hincapié en la búsqueda de los límites de lo decible, haciendo de este poemario, punto álgido y punto de inflexión, pues la palabra vareliana asume luego en los tres últimos poemarios, un tono bastante más sereno.

En esta exploración que implica desnudamiento, Blanca Varela ausculta e interroga, desde su propia circunstancia, los sentidos y los límites de esa humanidad que nos define. Para ello, su escritura, entre las diversas formas y estrategias que asume, va a acudir a algunas figuras, figuras extremas, figuras del otro, de lo otro. A lo largo de los ocho poemarios, cumplen esa función el ángel y el animal (en diferentes expresiones). Estos aparecen, por los valores que tienen en el imaginario colectivo, representación celestial e ideal, por un lado, y por el otro, naturaleza primaria terrenal, como dos manifestaciones que, desde lados opuestos, notifican, señalan las fronteras, los límites de lo humano, como ya lo decía Pascal ${ }^{14}$. Estas dos expresiones antitéticas, en el marco de la poesía de Varela, van a servir a una misma intención, a un mismo proceder, el ángel y el animal van a figurar una otredad que permite definir lo humano, encontrar su justa medida. Dentro del imaginario poético de Varela, el ángel, los ángeles operan como contrapunto a la o las figuras de animal.

\section{Hablar CON LENGUA DE ÁNGEL}

La constatación de un vacío de trascendencia aparece en la obra poética de la peruana como una constante, este vacío, esta ausencia es uno de los elementos que condicionan la experiencia de existente del/la sujeto vareliano/a; no sólo porque se explora la relación del yo con el mundo, los otros y consigo mismo desde la conciencia de los límites (terrenales y temporales) sino también porque se escenifica a lo largo de la obra la carencia, el desfallecimiento de lo divino en términos de nostalgia y de beligerancia. Dentro de este marco ontoteológico, el ángel constituye una figura significante. No es ocioso recordar que los ángeles son seres intermediarios entre Dios y el mundo; serían según los diferentes textos, seres puramente espirituales o dotados con un cuerpo etéreo, aéreo, que de los hombres sólo puede revestir las apariencias. Cumplen ante Dios las funciones de ministros: mensajeros, guardianes, ejecutantes

14. «Il est dangereux de faire voir à l'homme combien il est égal aux bêtes, sans lui montrer sa grandeur. Il est encore plus dangereux de lui laisser ignorer l'un et l'autre. Mais il est très avantageux de lui représenter l'un et l'autre. Il ne faut pas que l'homme croie qu'il est égal aux bêtes, ni aux anges, ni qu'il ignore l'un et l'autre, mais qu'il sache l'un et l'autre. L'homme n'est ni ange ni bête, et le malheur veut que qui veut faire l'ange fait la bête». (418). Pensées, Paris, Editions Garnier Frères, 1957, p. 174. 
de leyes o protectores de elegidos, y parecen obedecer a rigurosas jerarquías (Dionisio el Areopagita elaboró al respecto una extraordinaria teoría mística en sus Jerarquías celestiales). Para muchos autores, independientemente de los valores otorgados por las Iglesias y la fe católica, los atributos de los ángeles son considerados como símbolos de orden espiritual. Otros ven en ellos símbolos de las funciones divinas, símbolos de las relaciones de Dios con las criaturas o, inversamente, símbolos de las funciones humanas sublimadas o de aspiraciones insatisfechas e imposibles. De manera más amplia, los ángeles desempeñan el papel de signos de manifestación y presencia de lo sacro. Desde esta perspectiva, el ángel constituye una figura que vehicula y es portadora de un doble valor en la poesía de Blanca Varela: permite evidenciar las limitaciones de lo humano, del humano con respecto a las aspiraciones (imposibles) y a la idealidad y es, asimismo, revelador de la carencia de trascendencia, signo vacío que puede ser colmado o reinventado pero, paralelamente, signo que acompańa lo divino, en sus representaciones cristianas, y que como tal recibe la beligerancia.

Como punto de partida, y cualquiera que sea su valor, la figura del ángel introduce una otredad que crea en la escritura una nueva perspectiva, un nuevo ángulo para la mirada:

I

hombre en la ventana

mediopunto negro

ángel ciego o dormido

«Tàpies»

Canto villano, p. 135

Este poema, que forma parte de una serie de cinco breves textos titulada "Tàpies», constituye uno de los muchos ejemplos, en toda la obra de Blanca Varela, en que se demuestra que la pintura no sólo constituye una referencia explícita sino que opera en tanto que «activación de virtualidades singulares de 'visibilidad' en la escritura»' ${ }^{15}$. Aquí la poeta dialoga con la obra del pintor catalán, serie de cuadros/láminas, titulada Porta vermella, a fin de proponer otra mirada hacia ese «hombre» que es «mediopunto» que es «ángel ciego o dormido». El lenguaje visual introduce en el poético la posibilidad del paso de la mímesis figurativa a la abstracción, el poema de Varela parece detenerse a medio camino entre la representación y la reducción a ciertos rasgos y trazos. No sólo busca formas depuradas, significantes, sino que, en ese proceso y procedimiento, reduce al hombre a un objeto, o más bien a una simple forma. No como mera cosificación pues puede acoger diferentes sentidos e identidades

15. Daniel Lançon «Un ut pictura poesis contemporain », in L'acte créateur. Paris, PUF, 1997, p. 211-212. Citado por Modesta Suárez y traducido por mí. Como lo ha demostrado Modesta Suárez en su ensayo, Espacio pictórico y espacio poético en la obra de Blanca Varela, Madrid, Editorial Verbum, 2003, p. 15, lo pictórico « contribuye a modificar la manera de escribir el poema, de crear su espacio - poético- y tal vez su manera de ser leído». 
y puede verse, entonces, como una deshumanización (saludable) que lleva al ángel, pero a un ángel minusválido, no operacional, despojado de poderes: el hombre como un ángel desautorizado, castigado, caído. El ángel, a través de esas características, está ahí como figura más que como agente, figura que modifica la visión, la perspectiva que se puede tener sobre el hombre y lo humano. El no puede mirar, ya no mira, sin embargo, su presencia modifica nuestra mirada, su ceguera abre nuestra visión. La serie «Tàpies» se llama también "(puertas)», planteando como referencia explícita las láminas citadas del pintor. Pero, el término "puertas», así como la ventana de nuestro brevísimo primer poema, también sugieren que el espacio significante es el de los umbrales: en ellos, por ellos se define la humanidad ${ }^{16}$.

El ángel vareliano como ya lo anunciamos posee múltiples valores. Es, en primer lugar, una figura que, como ser intermediario entre Dios y el mundo, puede asociarse al vacío de trascendencia que metonímicamente se expresa a través del motivo de un cielo derribado, en ruinas:

II

$\cdots$

Atravieso el desierto,

La terrible fiesta en el centro del cielo derribado.

Estoy casi olvidando.

III

...

Contemplamos el cielo. No hay señales

$\cdots$

(p. 48) «Destiempo ", Ese puerto existe.

La mirada que soy entorna la puerta, atisba el vacío, otea el cielo en ruinas...

(p. 78) «Vals », Luz de día.

En esta representación de la desmiraculización del mundo, de la falta de una trascendencia escenificada como un cielo derribado, en que encontramos los «escombros del cielo» del poeta expresionista alemán Gottfried Benn, destaca como característica una vacuidad que recuerda de manera insistente la idea de carencia de valores trascendentes e identifica también un espacio vacante, que es el de un Dios ausente. Desde esa perspectiva, la figura del ángel aparece en ciertos casos en el imaginario vareliano como parte constitutiva de la representación divina, si pensamos en la definición del Salmo 18, 10-11 que hace de ellos seres celestiales, que le sirven de trono a Yahvé y son su ejército, su corte y su morada. Los ángeles forman parte de una coreografía divina pero

16. Como lo señala Modesta Suárez, en L'espace autrement dit, Jacques Dupin recuerda que « el realismo de lo simple y de lo elemental (en Tàpies) se aboca a revelar una obsesión del rastro humano en un mundo alienado ", op. cit., p. 55. Se reconoce pues una afinidad ontológica entre el pintor catalán y la poeta peruana. 
que se presenta como desfalleciente y degradada. Así aparecen, por ejemplo, en el poema "Destiempo", en el marco de un mundo, de una realidad de "cielo derribado», de un "cielo a jirones», en que la esfera celestial, divina es puro desorden, ha dejado de ser principio ordenador, sentido:

\section{$\mathrm{V}$}

Aquella torturada nube parecía tan firme,

ambulando,

desgarrando,

chocando con masas de ángeles.

(«Destiempo», Ese puerto existe, p. 49)

Los ángeles pueblan ese cielo vacío, de valores invertidos, lo escenifican: «arriba hay ángeles barbados que preguntan al viento qué poseen bajo el azaroso cielo (a más de tierra entre las uñas y el estigma del ajo en el beso capitoso y marica)» ${ }^{17}$. Integran la esfera de lo divino caído, vehiculan la nostalgia pero también la beligerancia. La relación de Varela con lo divino oscila entre el sentimiento de orfandad como nostalgia, por un lado, y por el otro, como abandono y desengaño. Ello se manifiesta paradójicamente en el reclamo de una relación con Dios pero que se acompaña de un descreimiento afirmado vigorosamente:

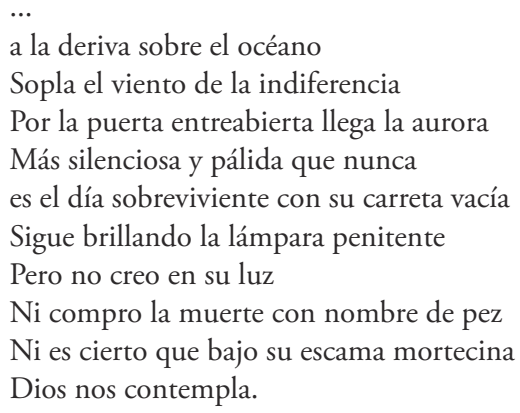

La experiencia singular vareliana de abandono, ausencia, desengaño se alimenta de esa «beligerancia frente a la religión» que Octavio Paz identificó como característica de la poesía moderna ${ }^{18}$ "fuente de su deliberada voluntad por crear un nuevo "sagrado" frente al que ofrecen las iglesias actuales". En Varela, de manera álgida en Valses y otras falsas confesiones, Canto villano y Ejercicios materiales, se va a desarrollar una beligerancia verbal, basada en imprecaciones, juegos blasfematorios, rebajamiento de las categorías, símbolos, figuras sacras, en el tratamiento paródico de las formas litúrgicas (como la plegaria), siguiendo la sulfurosa tradición que va de Baudelaire, Rimbaud ${ }^{19}$,

17. En «Crónica», Ejercicios materiales, p. 186.

18. Octavio Paz, El arco y la lira. México, Fondo de Cultura Económica, 1956, p. 118.

19. BV: «... en ese momento me interesaba más la poesía maldita. Al lado de Rilke me 
Lautréamont, hasta Dadá y los surrealistas. Poemas como «Divertimento» de Ese puerto existe, "El vals del Ángelus» de Valses y otras falsas confesiones, "Canto villano" y "Cruci-ficción» de Canto Villano son muestras palpables de esta beligerancia y constituyen relecturas y reescrituras disonantes, transgresivas, provocadoras de la historia sagrada, de sus figuras y de los valores vehiculados. En el marco de esta beligerancia, los ángeles en tanto que ejército o corte rodean a la figura divina negativa, dios asesino y verdugo:

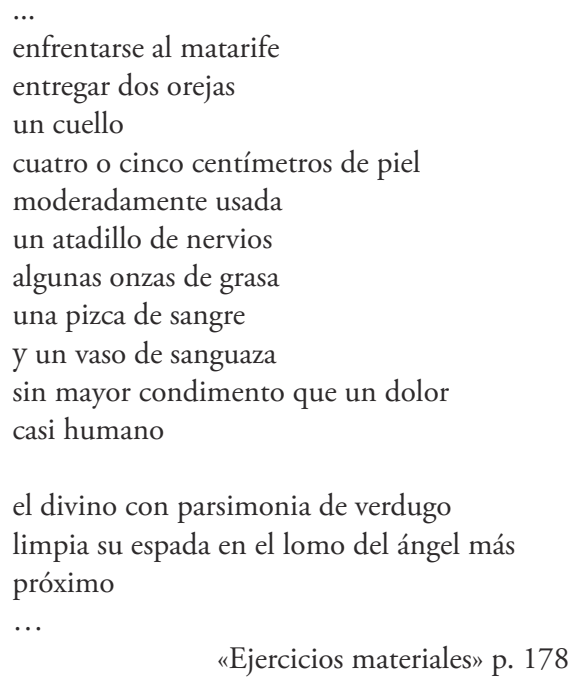

Como parte de la escenografía divina, el ángel acompaña a este dios representado como entidad de criminal y abusiva potencia ${ }^{20}$, pero que es también una entidad deficiente, venida a menos como lo dice poco antes el mismo poema:

gustaba Rimbaud. Nunca he tomado drogas, pero toda la poesía de la droga me parecía muy atractiva. Había en ella una parte del mal, no del de un espíritu que viene a ocasionar daño a otros, sino del mal que se hace uno a sí mismo, como purgando, buscando algo que hay que pagar para lograr no sé qué cosas. Me interesaba, me gustaba esa actitud maldita de quien está al filo, al borde de un abismo, que impreca y dice cosas terribles. Hay tal vez reminiscencia de eso, ligera, seguramente, en mi poesía. También leía a De Quincey y a Nerval, a Verlaine y a Baudelaire», en Efraín Kristal, «Entrevista con Blanca Varela». Mester Vol. XXIV, n² 2, 1995, p. 143-144.

20. Las diversas representaciones de dios como carnicero, matarife... lo figuran como un dios cruel, ávido que remite a las formas más antiguas tal como las define María Zambrano: "Mas el dios que el hombre siente sobre su vida de un modo "espontáneo", el dios "natural", es el que devora y destruye, el que reclama ser alimentado. El sacrificio lo aplaca momentáneamente. Un dios en quien se concentra y aparece esta pura potencia devoradora es Cronos en la vieja Teogonía de Hesíodo, a quien ningún sacrificio puede aplacar. Y éste parece ser la señal de la divinidad en su máxima potencia: lo que no accede al sacrificio, el fondo irreductible y rencoroso; lo implacable es la primera manifestación de lo divino", María Zambrano, El hombre y lo divino. México, Fondo de Cultura Económica, 1973, p. 125. El dios vareliano también tiene mucho del Dios despiadado e irascible del antiguo testamento. 


\section{.. \\ una interrogación cualquiera \\ rengueando al final del camino \\ un nudo de carne saltarina \\ un rancio bocadillo \\ caído de la agujereada faltriquera de dios \\ $\cdots$}

«Ejercicios materiales» p. 177

Se desarticula así, se descompone la coherencia y unicidad de la figura del ser supremo, en tanto que portador del principio de amor y de omnisciencia.

Además de esta función de auscultar la tensión con lo divino, la figura del ángel en el imaginario vareliano es una herramienta sumamente eficaz para el conocimiento de lo humano. A partir de su representación como seres espirituales o, como queda dicho, dotados con un cuerpo etéreo, aéreo, pero que de los hombres puede revestir las apariencias, se juega con la semejanza y la desemejanza, con esa otredad que permite cierta identidad. Así, la figura del ángel remite a ese estado que se concibe como fuera del mundo, intocable e intocado por las durezas de la existencia, como lo sugieren algunos versos: «renuncia el ángel a sus plumas, al iris/a la gravedad y a la gracia?»" Se trata de un estado que se esfuma al contacto con la realidad de la existencia, que queda destruido tras el trabajo de la conciencia, «entre mis dedos/ardió el ángel $\aleph^{22}$. El estar en el mundo aparece como una caída, a través de la imagen del ángel, aludiéndose al paso de un estado de inconciencia, de inocencia, de intangibilidad, a la adquisición de una conciencia:

\section{IV}

Porque ya no eres un ángel sino un hombre solo sobre dos pies cansados sobre esta tierra que gira y es terriblemente joven todas las mañanas.

Porque sólo tú sabes que hay música, jadeos, incendios, máquinas que escupen verdades y mentiras a los cuatro vientos, vientos que te empujan al otro lado, a tu hueco en el vacío, a la informe felicidad del ojo ciego, del oído sordo, de la muda lengua, del muñón angélico.

Porque tú gusano, ave, simio, viajero, lo único que no sabes es morir ni creer en la muerte, ni aceptar que eres tú mismo tu vientre turbio y caliente, u lengua colorada, tus lágrimas y esa música loca que se escapa de tu oreja desgarrada.

(«Auvers-sur Oise», Valses y otras falsas confesiones, p. 124)

La adquisición de una conciencia implica «limitarse humanamente», es decir, un mejor y más profundo conocimiento de la dimensión humana. Sería un error reducir el paso del ángel al humano a un acceso a la "sensatez», a la conciencia, es más bien, como lo dice el poema, estar más plenamente en una humanidad contradictoria y compleja, que sabe que poco puede ante sus pulsiones más hondas (de vida y de muerte), entre la eterna aspiración a la omnipotencia, las ansias de inmortalidad, la divinización de lo humano

21. «Conversación con Simone Weil», Valses y otras falsas confesiones, p. 121.

22. «Juego», Canto Villano, p. 130. 
y la realidad de la condición de ser viviente, que es ser cuerpo y animal; se trata de una humanidad contradictoria y compleja de la cual el arte, la poesía se alimenta, de la cual sólo el arte, la poesía pueden dar cuenta, porque el sujeto en toda su insuficiencia, desde su capacidad creadora, posee un saber que paradójicamente se desprende de su ignorancia, de su ceguera y sordera, de su orfandad metafísica. La evocación recurrente de la amputación, de la minusvalía de un órgano sensorial expresa la tentación permanente de cortarse, aislarse del mundo, de no estar completamente en el mundo, es decir, con toda la lucidez de la que se puede ser capaz, pero también aparece como lesión de existencia, rastro de la manera como ésta carcome, cercena y reduce el ser y su deseo $^{23}$. Es interesante observar cómo entra aquí el «muñón angélico» y cómo parte de la dimensión imaginaria del ángel, de su valor poético se desprende de la lengua biográfica de la poeta y del escrutamiento de su experiencia como sujeto/individuo (mujer):

EDGAR: En un poema de Canto villano dices que no bebiste el vino de la victoria sino tu propia sal, y la palabra sal es una palabra que se repite en tus anteriores libros ...

BLANCA: Bueno, digamos que la sal dejó de ser la sal poética, dejó de ser el mar abstracto, dejó de ser ciertas cosas y se convierte en lágrimas, una cosa muy precisa. Es como un viaje a mi persona. Me limito humanamente pero me siento más dueña de mi sal... Aceptar que tienes un rostro de alguna manera y que dejas de ser un ángel.. Porque hay un momento en que un poeta es un ser angélico o que se cree angélico ... Yo he vivido muchos años en ángel, hasta cierto momento. Creo que hasta el momento que tuve hijos ... que fue bastante tarde. Nada me tocaba, es decir, yo pasaba sobre las cosas y me sentía hasta invisible. Es una cosa muy curiosa ... Podía ser como una especie de testigo de todo; no me manchaban las cosas, no me tocaban. ${ }^{24}$

El evento biográfico que es fundamental en la vida de la autora, tal como lo dice ella misma es el nacimiento de sus dos hijos (Vicente en 1958, Lorenzo en 1961), la entrada en la maternidad, el «dar a luz» que coincide, es concomitante con el segundo poemario Luz de día que se presenta como el acceso, el aprendizaje de la lucidez:

En el momento en que tuve hijos, supe que ya no estaba sola y que ya no podía confinarme dentro de mí misma. Ya había salido de mi mundo interior. Te diré que hasta aquel momento me sentí un poco angélica, me desesperaba de la realidad y de los otros; volaba por cualquier lado; en fin, estaba en mis cosas. Cuando tuve a mis hijos, ya no pude: eran dos seres que estaban caminando y eran parte de mí. A través de ellos me comuniqué seguramente con los otros. La maternidad me hace aceptar mi feminidad, me hace aceptar que soy una mujer. Antes no lo había aceptado; yo quería ser una persona absolutamente asexuada. Con mi responsabilidad de madre nace otra persona. $^{25}$

23. Varela como otros poetas, Emilio Adolfo Westphalen, por ejemplo, parece decir a través de este motivo de la mutilación (materializado en el gesto de Van Gogh), de menoscabo de órganos esenciales para el arte, la creación -el oído, la mano, el ojo, la lengua- que son necesarios esos gestos extremos para renovar el gesto creador, desde el dolor, desde el sufrimiento y desde la necesaria supresión de nuestras habituales formas de ver, oír, hablar, gestos que también traducen un deseo de vuelta al silencio y a la oscuridad originales.

24. En O'Hara, op. cit. p. 17.

25. En Forgues, op. cit. p. 85. 
Presente de manera indirecta en dos poemas, "Antes del día» $\mathrm{y}$ "Madonna» (que aparecen en continuidad), la maternidad informa el conjunto desde la perspectiva de un recrudecimiento de la conciencia de existencia, que es central en ese poemario. «Dar a luz» es arrojar al mundo de la existencia:

«La vida llegará con avidez y ruido. Conocerán el sol. El mundo será esa claridad que nos pierde; los abismos de sal, la fronda de oscuras esperanzas, el vuelo del solitario corredor que se da alcance a sí mismo.» («Antes del día», p. 60)

La figura del ángel remite también, por consiguiente, a un estado de una anterioridad inocente o pura, asociada a la infancia (y juventud) como en el poema "Casa de cuervos» (de Ejercicios materiales), poema en que se recrea la experiencia de la maternidad, invirtiendo su valor consagrado de plenitud, y en el cual la figura del ángel aparece asociada a la del hijo:

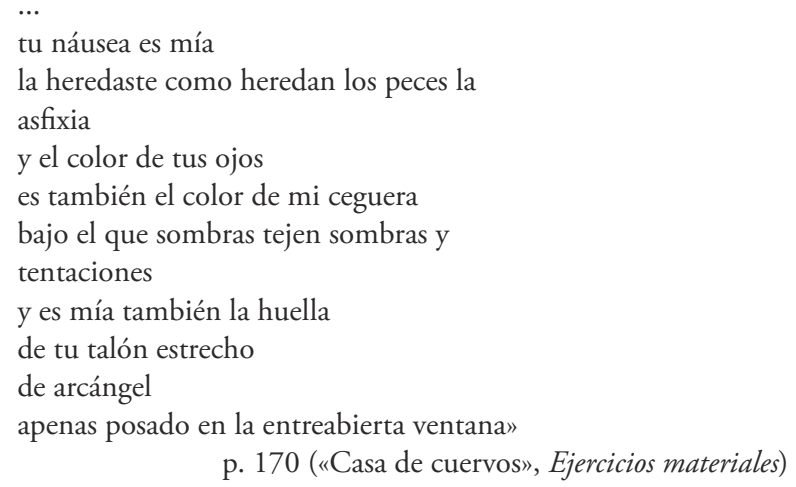

El hijo, engendrado, carne de la carne, aparece en sentido inverso como aquel del que se proviene, que deja su huella; es otro y es el mismo, es el mismo que deviene otro, la huella que le es propia, es la otredad del ángel, que escapa irremediablemente a la humanidad de la madre, y que vehicula algo como un tiempo no consumado, de inocencia, un estado no caído.

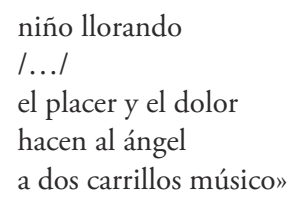

(Concierto animal, p. 221)

La figura del ángel al remitir a lo no contaminado por la dureza y la conciencia de la existencia abarca no sólo al nińo, sino también a los ausentes, a los que no participan de la realidad terrenal, es decir, los separados, adrede, por el sujeto (idealizados) o también por la muerte, como se ve en El libro de barro, poemario en que la ausencia de Dios, de lo divino deja de experimentarse desde la beligerancia, asumiéndose una nostalgia, en la cual la ausencia engloba lo divino y lo humano: 
«golpeaste tres veces la campana vacía y nadie respondió.(...) nostalgia de los ausentes, de los ángeles varios. Ellos, despojados del tiempo, se convierten en alusiva desnudez, en ausencia turbadora» (El libro de barro, p. 213).

Este valor se desprende en parte de la sublimación de las funciones humanas que reviste esta figura y, en ese sentido, debe ponerse en relación, en el caso de Varela, también con el ángel rilkeano. En efecto, como muchos poetas de su generación, la peruana fue una asidua lectora de Rainer María Rilke, y como lo ha reconocido, sus ángeles algo tienen, algo le deben al ángel de las Elegias de Duino ${ }^{26}$ y que el propio Rilke definiera en una carta (13/11/1925) como "criatura en la cual la transformación de lo visible en invisible, a la que aspiramos con esfuerzos, ya se ha llevado a cabo» ${ }^{27}$. El ángel de las Elegías es el ser que garantiza el reconocimiento en lo invisible de un rango, un nivel más elevado de realidad. Sin embargo, a diferencia del ángel rilkeano, esta figura en Varela no se establece en la definitiva separación con lo humano. Si bien están la añoranza rilkeana de la perfección y la autonomía del ángel, esta figura no vehicula, como sí en Rilke, un desprecio por la realidad humana, como tampoco la necesidad de superarla espiritualmente. En Varela, los ángeles son paradójicamente muy humanos, pueden emanar de la realidad prosaica y cotidiana, pero sin que se pierda de vista de que son portadores de lo invisible, es lo que dicen, por ejemplo estos versos de «Destiempo»:

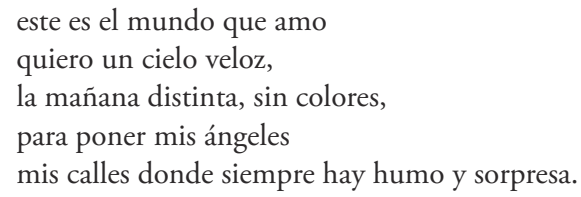

(Ese puerto existe, p. 48-49)

Los ángeles varelianos permiten medir, dibujar una humanidad, actúan como modelos, con claro valor ético, como lo afirma la poeta en una entrevista:

BV: A mí me preocupaba mucho eso y me ha preocupado además como modelo, inclusive personal. A mí me encantaba sentirme casi angélica; era una persona a la cual no la tocaban ciertas cosas.

EK: En tu poesía la imagen del ángel es recurrente.

BV: No hay ninguna premeditación en eso. Sucede que eliges porque te inclinas a ciertas cosas; son las corrientes naturales del alma, por decirlo de alguna manera.

26. EK: ... También hay ángeles en tu poesía. Pero, antes de que platiquemos sobre el tema en tus poemas, quería saber si te ha interesado o has reflexionado sobre el tema del ángel en la poesía de Rilke.

BV: Mucho. He leído mucho la poesía de Rilke, que era uno de los poetas favoritos de mi adolescencia y lo es hasta hoy. Pasé de Chocano a Rilke, lo que es un viaje tremendo. Leí Los cuadernos de Malte y después Las elegías de Duino. Fue una época maravillosa en la que a Lima llegaban todos los libros de Rilke desde Argentina, y creo que estaban bastante bien traducidos. En Efraín Kristal, op. cit. p. 141.

27. Martin Heidegger, Chemins qui ne mènent nulle part. Paris, Gallimard, 1962, p. 375 (Rilke citado por Heidegger). 
Además, creo en los ángeles.

EK: ¿Cómo son los ángeles en los que tú crees?

BV: No los puedo ubicar en una inmediatez pero creo que uno tiene encuentros con ángeles o que algunos seres humanos tienen la posibilidad de convertirse en ángeles en un determinado momento de su vida. El ángel como alguien que desciende, te toca y se puede ir. Conservar el ser angélico es muy difícil pero creo que es importante que exista la idea de esos ángeles, aunque sea como modelos de pequeñas transfiguraciones.

EK: ¿Y en qué consistirían esas transfiguraciones?

BV: En un cierto desprendimiento de las cosas y en una aceptación de no estar ligado a los pequeños apetitos. Poder, por ejemplo, comprender que alguien no te ame y encontrar que eso está bien, que es justo. ${ }^{28}$

\section{EN ANIMAL CONCIERTO}

Así como el ángel constituye en el imaginario vareliano una figura que descentra lo humano en su autosuficiencia moral y espiritual, pues recuerda las lindes de lo invisible, sacro, y de la intangibilidad y el desprendimiento, el animal, desde la vera opuesta desempeña una función similar. A lo largo de toda la obra de Blanca Varela, se reconoce la presencia constante de un bestiario variado, sus poemas están poblados de perros, simios, loros, gusanos, arañas... que no sólo forman parte del mundo, del entorno doméstico, sino que, en muchos casos, constituyen presencias que, en la diferencia y semejanza con lo humano, permiten dibujar con mayor precisión la condición de existente. Como el ángel, pero desde el otro extremo de la otredad, la figura del animal despliega diferentes valores y funciones. A manera de transición, y para mostrar que existen entre ellos, a pesar de la oposición que los caracteriza, puntos de convergencia (que Varela sabe crear, encontrar), cabe detenerse en la abeja vareliana. Figura central del poema "Así sea», de Luz de día, es portadora de la posibilidad de otra luz que la del día, es decir, de la realidad y de la conciencia cruda. La abeja vehicula la "gran luz», la «claridad total» asociada al sueño:

El día queda atrás,

apenas consumido y ya inútil.

Comienza la gran luz,

todas las puertas ceden ante un hombre

dormido,

el tiempo es un árbol que no cesa de crecer.

El tiempo,

la gran puerta entreabierta,

el astro que ciega.

No es con los ojos que se ve nacer

esa gota de luz que será,

que fue un día.

28. En Efraín Kristal, op. cit., p. 142-143. 


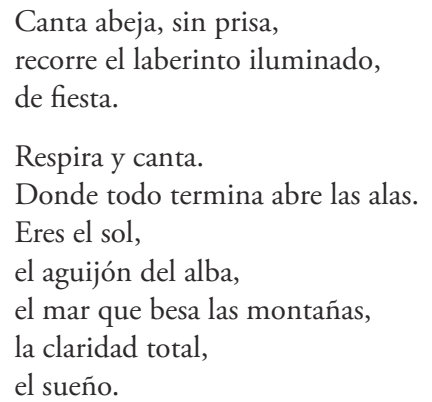

Este poema es paso a otra dimensión, a través del sueño en su doble sentido. Sueño como estado que corta con la realidad, como estado de reposo, suspensión de la conciencia, sueño que es o se asemeja a la muerte y también, universo imaginario interior pero que se presenta, no como espacio cerrado, sino de gran apertura, de vida más plena, de placer, («respira y canta»), de liberación («abre las alas») («todas las puertas ceden ante un hombre/dormido,»). Más que un espacio, es un más allá de «todo» (es decir del mundo, de la vida, de la realidad...). La envergadura es cósmica (.../el tiempo es un árbol que no cesa de crecer//el tiempo,/la gran puerta entreabierta,/el astro que ciega//...»), el título le imprime al poema un carácter hímnico, un valor religioso que luego alimentan los versos de arte mayor, endecasílabos en su mayoría, que, aunque pocos, estructuran el conjunto, así como la enumeración final y la carga expresiva generada por el asíndeton. El acceso a esta otra dimensión es acceso a otro saber, a otra visión «no es con los ojos que se ve nacer/esa gota de luz que será,/que fue un día», visión interior, imaginaria, onírica que permite «ver de otra manera» como lo deseaban los surrealistas, pero que aquí aparece cargada de un valor más bien ontoteológico. Como una contra-realidad, una realidad cuyo signo se ha invertido, hay camino, hay prueba, pero el signo no es el del dolor ni del esfuerzo sino el del placer, de la serenidad: "canta abeja, sin prisa,/recorre el laberinto iluminado, de fiesta». La encarnación de ese estado, la proyección del yo en la abeja es significativo: por el poderoso simbolismo positivo que vehicula (perennidad de la especie, animadoras del universo entre cielo y tierra, símbolos del principio vital, figuración del alma y del verbo) y también porque es un animalito de signo femenino, creador, que aporta alimento, que por sus colores y el cromatismo asociado a la miel es casi como una expresión material, terrenal de la luz, una mensajera como el ángel, ser intermediario que conecta con lo abierto, con lo cósmico. Más allá de la finitud, de la realidad del mundo y de la existencia. Este poema destaca como una "gran puerta entreabierta» con respecto a la exploración del túnel, a la experiencia del sujeto como existente, no es fortuito, en ese sentido, que de él haya sido sacado el endecasílabo que le da el título a la obra completa (reunida), «donde todo termina abre las alas».

Las múltiples correspondencias entre la hablante y el animal no sólo se limitan a la presencia de los animales que acompañan o ritman la existencia de los humanos o, como en este poema, que aparecen como símbolos y se cargan 
de un sentido suplementario. El animal, los animales y, en especial algunos de ellos, en la identificación y correlación que se dan, cuestionan la realidad de lo humano, del hombre como animal racional, y siguiendo a Jacques Derrida, cuestionan toda esa tradición :

(tradition) qui a toujours consisté, en effet, à opposer l'homme à tout le reste du genre animal, de façon essentiellement négative, comme dépourvu de tout ce qui est censé être le "propre" de l'homme: parole, raison, expérience de la mort, deuil, culture, institution, technique, vêtement, mensonge, feinte de feinte, etc. ${ }^{29}$

Es decir, toda una tradición filosófica inseparable de una posición de dominio y de un animal privado de logos. Importa en la poesía de Varela la noción derridiana del animal como ese otro viviente: "c'est un mot l'animal, c'est une appelation que des hommes ont instituée, un nom quills se sont donné le droit et l'autorité de donner à l'autre vivant» ${ }^{30}$, más aún con la mirada excentrada (y crítica) de una sujeto mujer, si seguimos a Derrida cuando afirma : "c'est le mâle qui s'en prend à l'animal, comme c'est Adam que Dieu a chargé d'asseoir son autorité sur les bêtes. "1 $^{31}$

La importancia de la figura del animal en la poesía de Blanca Varela se mide, en primer lugar, en la manera como éste participa en la constitución de la voz poética. En Ese puerto existe, poemario que posee el valor de ser, también y sobre todo, una entrada en materia, un acto inaugural con respecto a la voz que cobra existencia, se produce la asociación, entre el yo y el animal, en el movimiento inicial del texto «Primer baile» que gira en torno al yo que habla, definiéndolo, moldeándolo, otorgándole ciertas características:

Soy un simio, nada más que eso y trepo por esta gigantesca flor roja. Cada una de mis cerdas oscuras es un ala, un ser transido de deseo y alegría. Tengo veinte dedos hábiles y negros, todos responden a mi voluntad.

Tal vez soy el único viviente, el que se mueve, respira y se queja. El único en dar vueltas y girar sobre el lodazal y la culebra. El trompo, el girasol humano, velludo y limpio, el cantor solitario, el anacoreta, la peste. Soy, indudablemente, el que se oye, respirando, tejiendo para atrapar el acto, el testimonio erizado de ojos y lenguas todavía temblorosos, todavía con recuerdos.

¿Qué nos hace gemir y caer de rodillas? ¡Valor! Hay tiempo de sobra, que prosiga el festín. Luzcan airosos sus cráneos los convidados, sucios escarabajos atados a su memoria.

¿Debo decirles sólo para verlos palidecer que habrá que arrojarse al aire, rechazados por manos más poderosas hasta lo que es negro, sin eco, ni revés, ni umbral, ni término?

Amo esta flor roja sin inocencia.

29. Jacques Derrida, L'animal que donc je suis, Paris, Éditions Galilée, 2006, p. 10.

30. Ibid., p. 43.

31. Id. p. 144. 
En una modalidad, una suerte de versículo extremadamente largo que está como a caballo entre el verso y la simple prosa ${ }^{32}$, que va a ser recurrente en toda la obra de Blanca Varela, se afirma la voz poética; el sujeto que habla ya desde y con esta modalidad poemática más bien prosaica, problematiza lo lírico, en su acepción más tradicional; el hablante no es, pues, lírico, como se ve en la primera frase, no solo a través de la figuración animal del simio, sino porque además se aplica un carácter restrictivo, "soy un simio, nada más que eso, ...", dando a entender, como lo enunciará el conjunto del texto, que la circunstancia, lo que suscita la toma de palabra, no es de celebración o exaltación sino de rastreo, exploración de una situación existencial de desolación, de supervivencia. La animalidad que define aquí al yo, constituye una de las máscaras ${ }^{33}$ que van a ser una constante en la obra y que asume valores diferentes. Se trata de un proceder, sin embargo, que siempre aparece animado por la voluntad de crear una distancia esclarecedora con respecto a la humanidad del yo. La figuración por el animal introduce un juego entre lo mismo y lo otro (semejanza y otredad). Es significativo, por lo pronto, que aquí el animal escogido sea el simio. Antepasado peludo, que suele verse como imagen degradada del hombre, imagen despreciable que el hombre desea alejar de sí, mantener a

32. En la poesía de Varela la circulación es constante entre el verso y la prosa y el juego con las fronteras entre ambos también. Con respecto a esta modalidad, hay que observar que en la edición primera de Ese puerto existe no aparece como tal, es decir, una forma a caballo entre el verso y la prosa señalada tipográficamente por una sangría cuando el «versículo» continúa. Hay, por un lado, poemas en verso y, por el otro, poemas en prosa. "Primer baile» aparece como un poema en prosa. En la edición de la obra poética completa Cuando todo termina abre las alas, se introduce una distinción entre el poema en prosa y esta modalidad intermedia. En Luz de día, por ejemplo, segundo poemario de la autora, coexisten las dos formas. Se puede observar, sin embargo, que la modalidad que va a terminar por imponerse es la del «versículo».

33. Uso este término en el sentido que le da Emir Rodríguez Monegal : «El significado etimológico de [la] palabra [persona], ya se sabe, es máscara: en latín, la máscara del actor se llama persona. La máscara trágica no sólo sirve para ocultar el rostro; también ofrece una versión definitiva y estéticamente completa del personaje. Sirve asimismo para proyectar más lejos la voz, lo que aplicado a la poesía tiene su importancia. Como ha señalado Hugh Kenner al estudiar la teoría de la persona de Ezra Pound, la persona (la máscara) extiende el campo de la voz privada y personal del poeta, proyecta el yo más allá de sus límites subjetivos. Por medio de la persona el poeta sigue siendo yo y es otro. Esa dramatización crea y sustenta la voz individual y le da una autoridad de la que el yo particular carece. Esto lo entendió admirablemente Walt Whitman al crear no sólo un libro sino una persona. Una frase de Ezra Pound (que Kenner cita) resume inmejorablemente el proceso interior: «In the search for oneself, in the search for "sincere selfexpresion", one gropes, one finds, some seeming verity. One says "I am" this, that, or the other, and with the words scarcely uttered one ceases to be that thing ...» ("En la "búsqueda de uno mismo", en la búsqueda de una "expresión personal sincera", uno roza, uno encuentra, algunas aparentes verdades. Uno dice, "Soy" esto, o aquello, o lo otro, y apenas pronunciadas estas palabras uno deja de serIo ...»). Por eso, el yo del poeta (en toda obra lírica) no puede dejar de ser persona. De ese modo, paradójicamente, ese yo tan subjetivo de los líricos se convierte en un recurso fecundo, creador, para objetivar la voz, para crear la persona .. Inútil aclarar que al referirse a la máscara del poeta no pretende Pound, o su exégeta Kenner, hacer ninguna imputación de carácter moral. La máscara, la persona, es un artificio poético.» El viajero inmóvil, Buenos Aires, Editorial Losada, 1966, p. 19. 
distancia, caricatura del yo, brutal, codicioso y lascivo ${ }^{34}$. También está presente en la representación simbólica de este animal la bufonada, la payasada, valores que apuntan a fragilizar la posición del yo como hablante, la legitimidad de su palabra y su enunciación. A través de la figura/máscara del simio, se sugiere así no sólo que el sujeto va a hablar desde una humanidad cuestionada en su superioridad, en su integridad identitaria todopoderosa, sino que va a hablar desde esas zonas insondables, inconfesables de lo pulsional, del deseo que me parece están representadas por la "gigantesca flor roja»" Merece destacarse, asimismo, que en este poema y en todo el primer libro, la poeta asume una voz masculina, de la que se liberará después, es evidentemente la adhesión (aún no cuestionada) a la autoridad masculina, como exclusiva referencia del sujeto/ hablante lírico en el marco de la tradición. Sin embargo, funciona también como máscara, haciendo más flagrante el desfase entre la que escribe y el que habla en el poema. Hay en el fondo tres figuras: el simio/animal, el sujeto, yo masculino, y la poeta mujer (que no se autoriza a ocupar la función de sujeto).

Este poema que es entrada en materia y también acto de iniciación, acto ritual, a la manera de la presentación en sociedad de las jovencitas, como lo puede sugerir la noción de "primer baile» tiene, sin embargo, un carácter celebratorio equívoco, el texto rápidamente contradice lo festivo, revelando una voluntad antifrástica: lo que suscita la toma de palabra, no es de celebración o exaltación sino de rastreo y exploración de una situación existencial de desolación, de supervivencia; si hay festín es un festín macabro y los parámetros del estar en el mundo se señalan a través del «lodazal» y «la culebra», en una especie de escenario apocalíptico, en que el sujeto se presenta como el «único viviente». Es de notar, asimismo, que se enuncia la posibilidad multifacética del sujeto, máscaras o figuraciones que descentran identitariamente al yo pero que expresan al mismo tiempo, paradójicamente un protagonismo: no será éste manifestación narcisista sino más bien afirmación de una enunciación que habla no del mundo sino de la experiencia que el yo tiene del mundo, conciencia de sí en el mundo: «Soy, indudablemente, el que se oye, respirando, tejiendo para atrapar el acto, el testimonio erizado de ojos y lenguas todavía temblorosos, todavía con recuerdos». "Primer baile» tiene también una intención programática con respecto a la función del hablante/sujeto y a la misión de una exploración extrema, de los límites: «¿Debo decirles sólo para verlos palidecer que habrá que arrojarse al aire, rechazados por manos más poderosas hasta lo que es negro, sin eco, ni revés, ni umbral, ni término?».

La voluntad de trascenderse y extrañarse que caracteriza la obra de Varela implica desprendimiento, salida de lo conocido, separarse de las propias inhibiciones, de las censuras de la razón y de la norma, de las convenciones sociales, conlleva un desplazamiento, una descolocación del lugar de la

34. Como se analiza en el Dictionnaire des symboles, Jean Chevalier et Alain Gheerbrant, Paris, Robert Laffont/Jupiter, 1982.

35. La flor es en diferentes textos una figuración del deseo, de ese deseo informulable, inasible, inaudible. 
enunciación y del sujeto, como lo anuncia claramente ya en su título el poemario Canto villano:

Cuando me refiero a Canto villano es al canto de extramuro, o sea al canto que no se hace en el castillo; el canto no oculto. Yo hago esa especie de juego, indudablemente tiene que haber reminiscencias en esta especie de cosas de la canción popular; una cosa juglaresca tal vez. François Villon, el poeta francés, que era un tipo que hacía barbaridad y media y que era hasta un malhechor, cantaba. ${ }^{36}$

El canto debe ser «villano» en el sentido, entonces, en que se profiere desde un lugar otro, que implica la asunción de una violencia necesaria, no sólo lucha con, contra la palabra y su carácter artificioso y falso, sino también con respecto a las resistencias propias, interiores y también a las mundanas, sociales. Villano, entonces, es el canto que se excede, que no tiene conciencia moral, en el que el malhechor se apropia de la palabra, que desecha la medida, las normas y las convenciones del castillo, es decir, las reglas de urbanidad, moralidad, buen gusto, que no se reprime, que puede y debe ser desvergonzado, que no teme ser bajo, vil, feo, deforme. El libro Canto villano da cuenta, por consiguiente, de una escritura que se extraña y que se extrema. El término «barbaridades», detrás de su aparente llaneza e ingenuidad, dice con claridad una auscultación violenta, que se excede, que se sale de lo correcto, que es irreconocible, bárbara, enajenada con respecto a la imagen que de sí misma tiene la hablante/ sujeto y tienen los demás de ella ${ }^{37}$. En esta empresa de extrañamiento y de descolocamiento, el animal desempeña un papel esencial. Es interesante observar al respecto lo que dice en una entrevista la poeta sobre un animal en particular, el loro, que si bien solo tiene un rol casi decorativo en su poesía, acarrea detrás, diversos significados que complejizan la figura del sujeto en su función de poeta (registrador, cantor...):

EDGAR: Y qué otro animal...

BLANCA: Bueno, hay un primer animal interior. .. Hay un loro que me preocupa ... Hay un poema que se llama "Las cosas que digo son ciertas» y que está en Ese puerto existe. A ver. Fíjate ... Sí, en ese poema hay muchos animales: moscas. caballos. un loro ...

EDGAR: ¿El loro que te preocupa tenía una existencia fuera del poema?

BLANCA: No en particular. Mira qué curioso. Yo creo que ese poema lo escribí en París. Recuerdo que teníamos planeado con Octavio Paz hacer una revista que se iba a llamar "El pobrecito hablador" como el libro de Larra. Y no sé por qué en ese momento entré en la onda de que el poeta era un pobrecito hablador. ¡, Y qué es lo más próximo a un pobrecito hablador sino un loro? El loro, físicamente... Aquí en

36. Rosina Valcárcel, "Blanca Varela: "Esto es lo que me ha tocado vivir"», La casa de Cartón de Oxy 10, 1997, p. 6.

37. La villanía que permite una palabra desbocada, transgresiva, excesiva pero que al mismo tiempo quiere ser canto, juega desde y con el oxímoron no sólo para introducir una desconfianza ante la autenticidad de la palabra, los peligros de falsedad, sino también y sobre todo para abrir «el canto", violentarlo, es decir, confrontarlo con otros cánones de gusto que no son necesariamente los de la alta cultura, envilecerlo y regenerarlo en lo popular (no se despliega este canto muy lejos del vals (peruano) y sus excesos). 
Barranco, en la casa de una tía vieja, había un loro que decía lisuras ... Además de1 loro físico, digamos, yo era una india tropical en París. ¿Te das cuenta? ¿Y qué debe tener una latinoamericana india en París? ¡Un loro! No puede tener otra cosa, ¿no te parece? Además es un poco Rousseau, un poco todo eso, la idea del loro, del exotismo ... Además los franceses son muy exóticos, esperan que uno tenga plumas, un loro ... No había nada que hacer. ${ }^{38}$

Además de jugar con la idea de lo exótico (lo otro, por animal y como representación del otro para el occidental/europeo) se trata de un doble del yo que habla, como un extremo peligro, abuso de la palabra que anula la palabra: el poeta es «pobrecito hablador»; pero también animal que dice sin represión y que, evidentemente, mucho tiene que ver con el ulterior villano que dirá barbaridades. Blanca dice "no hay que tenerle temor a ninguna palabra» ${ }^{39}$, el loro, animal que dice «lisuras», (peruanismo que significa groserías) es decir, las cosas que nadie más se atreve a decir le permite liberar su propio proceder.

Sería, sin embargo, errado pensar que la empresa vareliana de extrañamiento se construye sólo en el exceso, en la transgresión. En tensión o en concomitancia con el "canto villano», se despliega una voz que no es ni grito, ni queja, ni burla, que se sitúa más acá del canto o la canción, en un espacio ya no social o sociable sino de intimidad (cercano a la confesión), como lo afirma el poema «Media voz»:

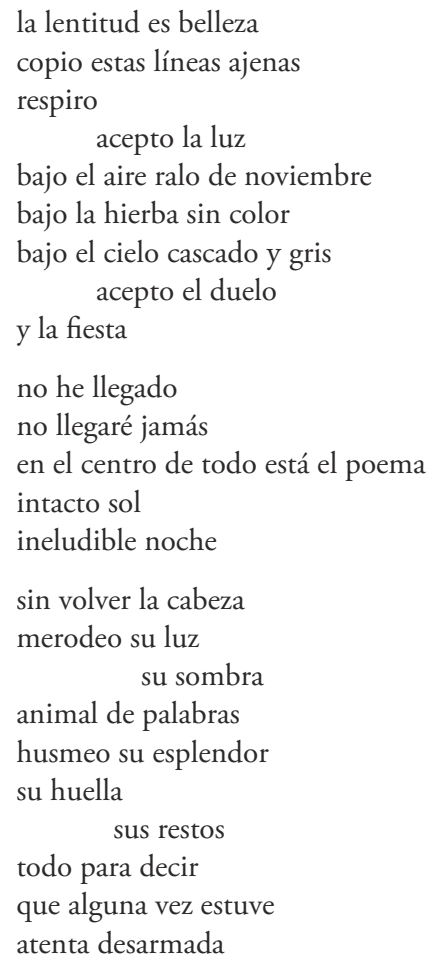

38. En O'Hara, op. cit. p. 13.

39. Ibid. 
sola

casi en la muerte

casi en el fuego

El título sugiere que se trata de una palabra que se oye primero como voz, pero no es «a media voz» sino «media voz», una manera, una circunstancia considerada como sustancial, característica del ser (en que como dice con acierto Américo Ferrari «la mitad es voz, la otra mitad silencio»). ${ }^{40}$ Esta «media voz» es también la de cierto lirismo que contrasta con la del "canto villano" pues se suspende el prosaísmo. Media voz es primero silencio y lentitud, parece instaurar una tregua en el combate. Paradójicamente, los primeros versos hablan de una voz hecha de otras voces, pero una voz que no se oye (inaudible) que se escribe, que respira, un sujeto que en lugar de hablar, respira. El verbo que adquiere posición central en el espacio del poema, «aceptar», ratifica esa idea de tregua y sugiere que el sujeto se deja penetrar por la realidad aunque esta sea insatisfactoria; estar en ella, ya no considerarla con distancia y desconfianza. Tregua y derrota en apariencia, como lo introduce la doble construcción negativa de la segunda estrofa. Sin embargo, lo que prevalece no es un sentimiento de derrota sino el reconocimiento y la identificación de un centro que es un sentido último en medio de una realidad, de un mundo complejo, sin trascendencia ni sagrado, de apariencias y simulacros. "No hay centro (a pesar de todo) vamos al centro y el poema está en el centro de todo. La improbable llegada al centro equivale, a través de todos los poemas, a la improbable llegada al poema, camino sin fin", como lo sugiere Américo Ferrari ${ }^{41}$. Aquí el poema fugazmente como centro se reviste de un valor sagrado, en una escenificación ritual (simple, primitiva) en la cual la hablante es "animal de palabras», es decir, criatura menos que humana, despojada de una humanidad soberbia, pero humana por la palabra. En otro registro, en otro tono que el del grito o el de la imprecación, el decir es siempre, no deja de ser, reconocimiento de una experiencia existencial, un estar en el mundo, "alguna vez estuve...», y la gravitación en torno a un centro inalcanzable que contiene lo impronunciable, lo inconfesable, lo desconocido adquiere sentido en la medida en que es desnudamiento, exposición, riesgo por y en la palabra.

Los animales del bestiario vareliano se presentan más que como una población autónoma, como espectadores atentos y contiguos del humano («el ratón te contempla extasiado/la araña no se atreve a descender ni un/milímetro más a la tierra/...», «Lady's Journal $\aleph^{42}$ ) y sobre todo como máscaras o «personas», dobles semejantes y diferentes, al mismo tiempo. Desde estas dos posiciones, dibujan al existente, al humano, «dulce animal, tiernísima bestia que te repliegas en el olvido para asaltarme siempre...» («Último poema de junio») ${ }^{43}$. El animal,

40. Américo Ferrari, «Varela : explorando los ‘bordes espeluznantes’ ». Hueso Húmero. N², 1986, p. 137.

41. Ibid, p. 141.

42. Canto Villano p. 145.

43. Ejercicios Materiales, p. 166. 
según Gilles Deleuze, es, por definición, lo que siempre está alerta, al acecho, a la defensiva ${ }^{44}$. Desde este valor, la homología humano/animal que establece Varela se da para recordar nuestra imperfección, vulnerabilidad, desamparo, que, a menudo, se esconden detrás de la inmensa soberbia que caracteriza al humano. $\mathrm{Y}$ es muy significativo que uno de los poemas preferidos de la poeta sea justamente el titulado «Persona» que asume la animalidad ${ }^{45}$, como memoria y presente de lo que somos:

\author{
el querido animal \\ cuyos huesos son un recuerdo \\ una señal en el aire \\ jamás tuvo sombra ni lugar \\ desde la cabeza de un alfiler \\ pensaba \\ él era el brillo ínfimo \\ el grano de tierra sobre el grano \\ de tierra \\ el autoeclipse \\ el querido animal \\ jamás cesa de pasar \\ me da la vuelta
}

El animal, la figura o categoría de animal permite auscultar mejor, en ese vaivén entre otredad y semejanza, el fondo ontológico, el ser. En «Persona» la homologación animal/persona y, sin olvidar también detrás, el valor de máscara del término "persona», descentran lo humano, su unicidad y su autoridad. Dice la autora al respecto:

el poema) habla de un animal que se da la vuelta, que es el ser. No me acuerdo en este momento, tal vez ese (poema) es con el cual más me identifico, es mi sello personal al mismo tiempo. No hay un perro allí, pero hay esa especie de individuo que da vueltas, se muerde la cola, se pregunta, indaga y sabe que los demás van a cierto destino. ${ }^{46}$

\footnotetext{
44. En L'abécédaire de Gilles Deleuze, (3 DVD) de Pierre-André Boutang, Paris, Ed. Montparnasse, DVD 1.

45. Sobre la animalidad, el Dictionnaire des Notions philosophiques - Encyclopédie Philosophique Universelle, dice lo siguiente: « c'est le dualisme cartésien qui sépare l'âme de la matière. L'hommesujet pensant- de l'animalité. L'animalité chez les classiques n'est que la figure de l'existence naturelle, immédiate et finie, opposée à la transcendance de l'esprit. (...) On en vient parfois à dénommer animalité l'autre de l'esprit, en nous; ce qui n'est point (nous semble-t-il) mécanisme mais désir, que l'esprit croit devoir (et pouvoir) nier pour être [...pur] (cf. Kant : la discipline doit " dépouiller " l'homme de son animalité, Réflexions sur l'éducation ; (cf. aussi Alain). Le fantasme s'épanouit librement dans la "bestialité " au sens commun, qui est une animalité mythique, chargée de porter nos péchés, d' « expliquer " notre inhumanité, c'est-à-dire notre impensable humanité » (B. Gremmi).

46. Rosina Valcárcel, "Blanca Varela: "Esto es lo que me tocado vivir"». La casa de Cartón de Oxy, 10, 1997, p. 12.
} 
Si bien, con respecto al poema citado, Varela descarta la identificación con el perro, éste innegablemente es modelo, es recurrente como figura, como alter del humano ${ }^{47}$, en la proximidad doméstica, en la sumisión e inferioridad: «un alma sí un alma que anduvo por las ciudades/vestida de perro y de hombre/un alma de gaznápiro», "Camino a Babel $»^{48}$.

El escrutamiento de la humanidad, a través de la figura del animal, se presenta, en el conjunto de la obra, a través de variadas posibilidades retóricas y poéticas. Es, por ejemplo, sumamente rica la explotación de esta figura en el poema de Ejercicios materiales titulado «Ternera acosada por tábanos»

\author{
podría describirla \\ ¿tenía nariz ojos boca oídos? \\ ¿tenía pies cabeza? \\ ¿tenía extremidades? \\ sólo recuerdo al animal más tierno \\ llevando a cuestas \\ como otra piel \\ aquel halo de sucia luz \\ voraces aladas \\ sedientas bestezuelas \\ infamantes ángeles zumbadores \\ la perseguían \\ era la tierra ajena y la carne de nadie
}

47. La figura del perro se ve nutrida por una experiencia relevante para la autora:

EDGAR: Esa anécdota con el perro, ¿la recuerdas'?

BLANCA: Sí, sí... Eso fue una cosa muy particular ... Yo creo que volvía de Estados Unidos ... El retorno al Perú -cada vez que he estado fuera- siempre me produce una especie de inmensa depresión. Porque encuentro, bueno, las cosas que sabemos que existen pero que no vemos cuando estamos aquí. Vivimos cada uno dentro de un túnel que mira más o menos a sus cosas y es la pobreza, la aridez, el abandono. Entonces un día caminando por la calle, así, crucé la esquina y había un animal, un perro, no recuerdo si era uno de esos perros chuscos, amarillo, verde ... Lo cierto es que el perro me miró, ese perro me miró ... Yo sentí una cosa terrible, algo que se me quebraba interiormente, tremendo. Sentí toda la compasión del género humano concentrada. Es decir, me pareció que era una mirada con toda la dignidad de un animal, que es el hombre también para mí, no sé ... Yo creo que ahí entró el perro a mi vida y a mi poesía» (op. cit. p. 13).

Esta experiencia sitúa a Blanca Varela en esa posición de no dominación, fuera de la postura del hombre (postura de superioridad masculina) que sabe y observa al animal, Varela está en las antípodas de la posición de esos, como dice Derrida "(qui) ne se sont jamais vus vus par l'animal; ils n’ont jamais croisé le regard d'un animal posé sur eux (sans même parler de leur nudité); si même ils se sont vus vus, un jour furtivement, par l'animal, ils n'en ont tenu aucun compte (thématique, théorique, philosophique), ils n'ont pu ou voulu tirer aucune conséquence systématique du fait qu'un animal pouvait, leur faisant face, les regarder, vêtus ou nus, et, en un mot, s'adresser à eux; ils n'ont tenu aucun compte du fait que ce qu'ils appellent "animal" pouvait les regarder et s'adresser à eux depuis là-bas, depuis une origine toute autre.» (op. cit. p. 31).

48. Canto villano, p. 156. 


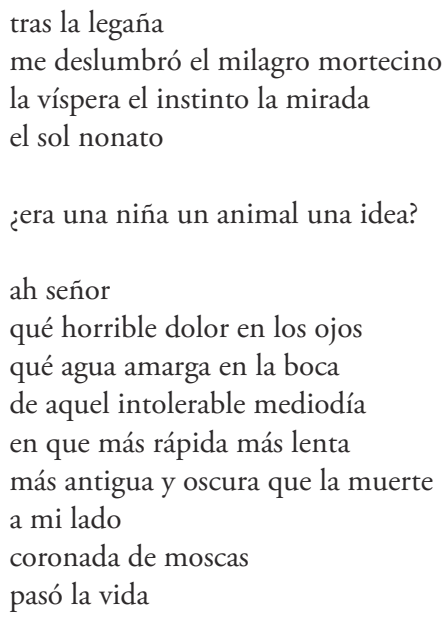

La visión de la vida que se desarrolla aquí aparece, no como energía creadora, fuerza positiva, sino como una lógica despiadada, voraz, destructiva, pues (probablemente) se han olvidado los valores humanos (como la justicia, la compasión, el amor, el respeto...). Es la humanidad la que se pone en tela de juicio: el poema, de manera alegórica, sugiere que, en ciertas situaciones y circunstancias, el umbral de lo infrahumano se franquea. Se borran, se difuminan los rasgos distintivos de lo humano y, para expresarlo, está la figura del animal, de la ternera, por un lado, y de los tábanos, por el otro. El horror, lo intolerable de la escena, de la situación radica en el acoso, esto se juega a través de los adjetivos calificativos, "halo de sucia luz», "voraces aladas/ sedientas bestezuelas», «infamantes ángeles zumbadores», «horrible dolor», «agua amarga», «intolerable mediodía», y se complementa con la subjetividad y las reacciones del/la hablante que no sólo cuenta sino que describe y expresa sus sentimientos ante lo que ve (estrofa 7), en un crescendo emotivo, en una queja y denuncia. Detrás del animal lo humano: salirse de la humanidad, porque desgraciadamente la humanidad no siempre es sinónimo de humanismo, entrar en lo animal para demostrar lo inhumano, lo infrahumano. La fuerza del poema radica en su ambigüedad, en la circulación entre las dos isotopías, lo humano y lo animal, el texto además de emparentarse con la alegoría e incluso la parábola, también tiene algo de fábula invertida, por el tipo de isotopías: mundo de lo humano y mundo del animal (tradición esópica). No hay nada más, metafísicamente hablando, que la intolerable vida, la sucia y degradada realidad.

Concierto animal y El falso teclado, los dos últimos libros de la poeta, abordan la cuestión de la muerte: ésta es central, vertebra la palabra vareliana última y aquí también, en esta estancia poética final, el animal está presente, muy presente. En dichos poemarios, la empresa verbal posee una doble dimensión paradójica, contradictoria: humanizar la circunstancia de la muerte (que la poeta siente como próxima) y, al mismo tiempo, considerarla en su radical 
extrañeza, en la imposible apropiación. La lengua trabaja en el doblez, desde el cuerpo y su finitud y también desde el ansia de trascenderse. El poema «El falso teclado", que le da nombre al último libro de Blanca Varela, aparece como el punto culminante del camino, del acercamiento por la palabra a la muerte. Sin que se abandone la necesidad de corroer la unicidad y autoridad de la palabra, expresada en el valor autorreferencial de la mayoría de los títulos de sus poemarios, aquí a través del calificativo "falso», «El falso teclado» como título y como poema constituye además una clave que conecta la poesía con lo sagrado (el silencio y lo invisible):

toca toca
todavía tus dedos se mueven bien
el dedo de la nieve y el de la miel
hacen lo suyo
nada suena mejor que el silencio
nuestro desvelo es nuestro bosque
aguza el oído como una hoz
a trillar lo invisible se ha dicho
para eso estamos para morir
sobre la mesa silenciosa
que suena$$
\text { p. } 260
$$

El falso teclado es metáfora del quehacer poético, en la analogía musical, el ejercicio silencioso y tenaz del músico sobre teclas pintadas en la mesa o en un piano mudo. En la proximidad de la muerte se alcanza lo quintaesenciado, ese silencio primero que anida en la poesía, del que se desprende la poesía. El hacer sonar el silencio, el "trillar lo invisible» como tareas de la poesía, le otorgan a ésta un valor sagrado ${ }^{49}$, expresando así manifiesta afinidad con la obra de José Angel Valente (por lo demás, este último libro le está dedicado), para quien la palabra poética es portadora de una dimensión otra, que trasciende lo verbal, "un mundo de realidad que el lenguaje no puede expresar», pero que está "sumergido en el lenguaje mismo» ${ }^{50}$. «El falso teclado» parece acoger dicha lectura, pero ésta viene inextricablemente asociada a la muerte. La proximidad de la muerte enseńa, abre a lo desconocido. Se plantea como un acto iniciático, la mesa de la escritura, de la creación aparece como mesa del sacrificio ritual.

49. Lo sagrado es por definición lo «inexpresado» y lo «inexpresable». Heidegger afirma que lo «ignoto» se aloja en el lenguaje a través del silencio. Gracias al silencio, solo por él, lo sagrado puede ser transportado hasta dentro de la palabra del canto. El silencio se presenta como la vía para acercarse a lo inalcanzable, para pertenecer a lo que no se dice. La tensión entre palabra y silencio plantea lo sagrado como paradoja de que es deber de la poesía hablar y sin embargo/a sabiendas de que hablar es imposible, como lo recuerda Maurice Blanchot, en La part du feu. Paris, Gallimard, 1949 p.128-129.

50. José Angel Valente, «Formas de lectura y dinámica de la tradición», La experiencia abisal. Barcelona, Galaxia Gutenberg-Círculo de lectores, 2004, p. 149. 
Pero la dimensión ontoteológica que se puede rastrear aquí convive con una preparación para el morir que podría situarse en las antípodas del valor sagrado, pues apela a lo profundamente humano, y más aún, a lo más primario, a lo animal. La preocupación central que es la finitud humana y la necesidad de una «preparación» debe entenderse en función del contexto, de la situación existencial de estar fuera de todo sistema religioso o moral, y en ese sentido, como lo observa Fernando Savater, se plantea la pregunta de una buena o mala muerte, de la posibilidad de morir auténticamente ${ }^{51}$. La cuestión de la autenticidad en la poesía de Varela constituye uno de sus motores principales y en el contexto de la muerte no deja de serlo, por supuesto. Se manifiesta en la voluntad de auscultar esa cercanía, la experiencia de esa proximidad, escrutándose la hablante/sujeto a sí misma en esa inminencia. Pero, es, sobre todo, a través de la figura del animal como logra traducir mejor esa autenticidad buscada. Como un paso obligado, la poeta vuelve a la figura del animal para no olvidar que

Ser sencillamente un animal significa proseguir la línea irremediable de la especie, asumirse como hijo de unos padres mortales a quienes nuestro nacimiento primero y crecimiento después desalojará fatídicamente del mundo, para ejercer luego nuestra capacidad genésica y procrear descendientes que ejercerán con nosotros la misma abolición. $^{52}$

En Concierto animal, lo animal abre y cierra el poemario y su peso simbólico está dado también por el hecho de estar contenido en el título del conjunto, un conjunto $^{53}$ focalizado en la preparación al morir. Si bien no todos los poemas versan sobre la muerte, se puede decir que el libro propone «variaciones» en torno a esta preocupación. Como en otros títulos de la obra de Blanca Varela, o más bien en la mayoría, se suman los sentidos, entre los cuales, el metapoético que no exalta lo poético sino que lo considera desde abajo o desde una ajenidad, a distancia. Lo metapoético está dado por el término "concierto", tomado en su acepción más conocida o frecuente: «composición musical para orquesta y uno o varios instrumentos solistas ${ }^{54}$. Se crea una suerte de oximorón entre el concepto de "animal» y el de "concierto", entre lo primario, instintivo, (y por ello inarmónico) y lo humano culturalmente elaborado, organizado según la razón y la imaginación, regido por el principio de la armonía. Lo animal en el primer poema, como en el título del libro, más que una figura es un atributo:

$$
\begin{aligned}
& \text { Niño come llorando } \\
& \text { llora comiendo niño } \\
& \text { en animal concierto } \\
& \text { el placer y el dolor } \\
& \text { hacen al ángel } \\
& \text { a dos carrillos músico }
\end{aligned}
$$

51. En «¿Vida buena o vida eterna?», La vida eterna, Barcelona, Ariel, 2007, p. 111-121.

52. Ibid., p. 58.

53. Se trata de veintiún poemas en verso, sin título.

54. Diccionario del español actual, Manuel Seco, Olimpia Andrés, Gabino Ramos, Madrid, Aguilar, 1999. 
Aparece la formulación del título invertida, ampliando el sentido del sustantivo "concierto": a lo musical, presente también de manera explícita, se agrega claramente el sentido de "convivencia o relación pacífica», «buen orden y organización", dos actividades que coexisten, que se conjugan sin excluirse (en los versos 1 y 2 , con el quiasmo). Lo propio del animal es la ausencia de jerarquías, de conciencia racional: el alimentarse, que es elemental, instintiva necesidad se da aunque haya dolor, pena, sufrimiento. La lengua a través de la cual se va a hablar es la que pone en relación diversas figuras al margen del hombre adulto, ser racional: si bien no pueden homologarse completamente, el niño, el animal, el ángel son todas expresiones de lo que escapa a una humanidad «definitiva» y "acabada», y que, por eso, son capaces de reflejar la tensión entre lo otro y lo mismo (extrañeza e identidad). En la perspectiva del conjunto, se crea, a través de esta combinación, una nueva realidad verbal tan paradójica o inconcebible como lo es la muerte para cada uno de nosotros. El concierto/ desconcierto que es la muerte. Y al cabo de la lectura del libro se plantea que para morir, quizá, hay que aprender a cantar, o que sólo se puede cantar como un animal. Es, me parece, lo que enuncia el último poema:

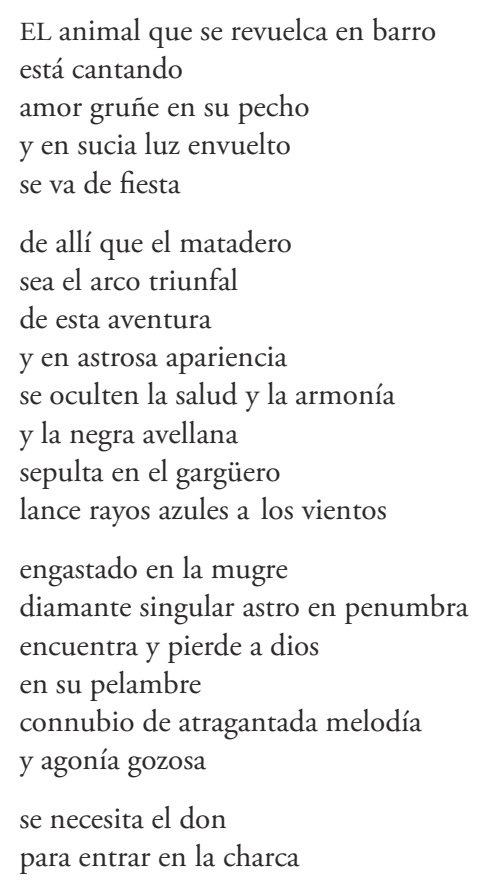

El animal de este poema que cierra Concierto animal y que podemos identificar por su acción y su medio (revolcarse/barro) con el cerdo cuyo destino es el matadero (estamos lejos del cordero sacrificial, sagrado), aparece como expresión extrema de desacralización, desmitificación de la muerte. Este mismo animal aparecía ya en Canto villano, uno de los textos más sulfurosos que le daba el nombre al conjunto. Estaba presente no como ser viviente sino como alimento y metáfora de existencia «y de pronto la vida/en mi plato de pobre/un 
magro trozo de celeste cerdo/aquí en mi plato» (p. 140). Diferentes elementos construyen la desmitificación aquí, a partir de la figura referencial del animal: la identificación con el cerdo (como animal innoble, bajo), el contexto de barro y mugre, la degradada trascendencia a través de la luz «en sucia luz envuelto» y la aspiración mística, la vinculación de dios con este animal «encuentra y pierde a dios/en su pelambre». A la fórmula "concierto animal»/ «animal concierto» le hacen eco aquí "el animal.../está cantando», "amor gruñe en su pecho» y "connubio de atragantada melodía y agonía gozosa». Disonancia, inarmonía que lo primario engendra, lo primario del animal y de la muerte como circunstancia vital. Sin embargo, más allá de la intención degradante, la figura del animal es portadora de valor, es, en ese sentido, «diamante» pues permite la revelación, permite, desde su otredad, un mejor y más profundo conocimiento de la muerte humana. Los dos últimos versos que cierran el poema dan la clave del valor atribuido al animal, el "don para entrar en la charca», que puede asociarse a la experiencia de la muerte desde la perspectiva de una animalidad que es no conciencia. Como lo dice Maurice Blanchot, «el ser del animal es para él sin fin, sin contorno y sin mirada sobre su estado», el animal «entra en la realidad sin tener que ser el centro de ella ${ }^{55}$. Es la conciencia de nuestra condición de mortales, como lo subrayó, a su vez, Georges Bataille, lo que nos diferencia de los animales, los cuales, si están en la naturaleza «como el agua en el agua ${ }^{56}$, o sea, sin extrańeza ni conciencia alguna con respecto a lo que los constituye y a cuanto los rodea, es porque ignoran la fatalidad de su muerte, fuente de toda extrańeza humana. Es esa misma conciencia la que Miguel de Unamuno en Del sentimiento trágico de la vida define como una enfermedad: «El hombre por ser hombre por tener conciencia, es ya, respecto al burro o a un cangrejo, un animal enfermo. La conciencia es una enfermedad ${ }^{57}$. La no conciencia de la condición mortal que según la tradición filosófica caracteriza al animal permite al poeta, a la poesía acercarse a la muerte desde esa orilla ajena, como lo hace Rainer María Rilke en la Elegía VIII, «pues junto a la muerte ya no se ve la muerte/ y hacia fuera se observa, acaso con gran mirada animal». ${ }^{58}$ Es también en torno a ese mismo motivo, pero de manera más demostrativa, que gira el conocido poema de De Vigny, «La mort du loup» en que la muerte del animal suscita admiración y es objeto de enseñanza:

\footnotetext{
Hélas ! ai-je pensé, malgré ce grand nom d'Hommes, Que j'ai honte de nous, débiles que nous sommes! Comment on doit quitter la vie et tous ses maux, C'est vous qui le savez, sublimes animaux!
}

55. Maurice Blanchot, «Rilke ou l'expérience de la mort », L'espace littéraire, Paris, Gallimard, 1955, p. 176 (mi traducción).

56. Georges Bataille, L'expérience intérieure, Paris, Éditions Gallimard, 1954 (mi traducción).

57. Miguel de Unamuno, Del sentimiento trágico de la vida, Madrid, Espasa-Calpe, 1913, p. 39.

58. Rainer Maria Rilke, Elegías de Duino, Lima, Pontificia Universidad Católica del Perú, 1997, p. 63. 
A voir ce que l'on fut sur terre et ce qu'on laisse

Seul le silence est grand ; tout le reste est faiblesse.

- Ah ! je t'ai bien compris, sauvage voyageur,

Et ton dernier regard m'est allé jusqu’au coeur !

Il disait : "Si tu peux, fais que ton âme arrive,

A force de rester studieuse et pensive,

Jusqu’à ce haut degré de stoïque fierté

Où, naissant dans les bois, j’ai tout d'abord monté.

Gémir, pleurer, prier est également lâche.

Fais énergiquement ta longue et lourde tâche

Dans la voie où le Sort a voulu t’appeler,

Puis après, comme moi, souffre et meurs sans parler". ${ }^{59}$

A diferencia del hombre, el animal/el lobo sufre y muere sin soltar ni una queja, ni un grito, ni una plegaria, «este silencio es el hecho no sólo de la dignidad más elevada - de la entereza ante la muerte- sino también de la inocencia misma, de la no participación del animal a las fábulas humanas, a los mitos violentos que hacen de ella una víctima ${ }^{60}$. En El falso teclado, la figura del animal, con estos valores, es pieza clave pues cierra el conjunto:

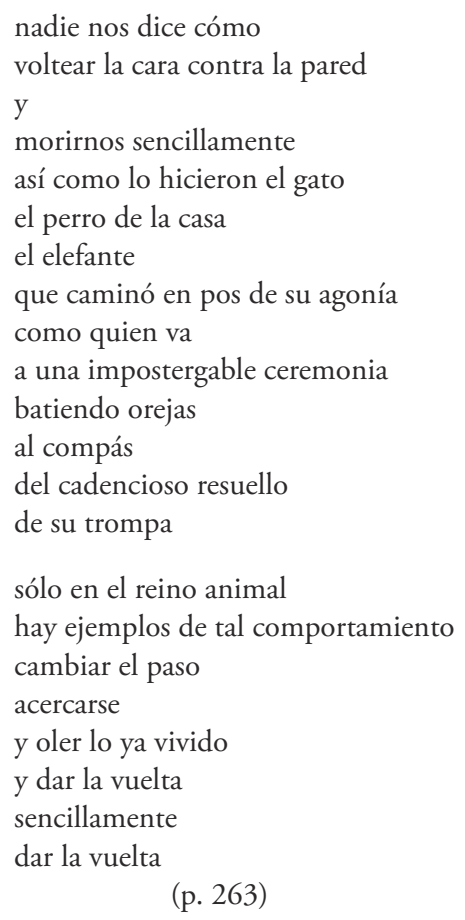

«Nadie nos dice» es no solo el último poema del libro, sino también y sobre todo el último poema de la obra poética reunida, cierra la obra, pone un

59. In Les destinées, 1864, de Alfred de Vigny.

60. Jérôme Thélot, La poésie précaire, Paris, Presses Universitaires de France, 1997, p. 14 (mi traducción). 
punto final desde la incertidumbre y el desamparo que genera el enfrentar esa circunstancia definitiva, sugiriendo que no hay mejor enseñanza, quizá también la más humilde, la más sencilla que la del animal ante la muerte. Hablando con el animal, desde el animal (de lo más doméstico a lo más agreste, de lo ordinario a lo ceremonial), desde ese origen otro, que no excluye el sufrimiento ni la experiencia de la muerte, Blanca Varela quisiera decir la muerte con el silencio animal, alejarse de la palabra pensante, de la queja y la plegaria y, por eso, estos últimos versos asumen una forma escueta, sin adorno ni pathos pero extraordinariamente eficaz y poderosa.

La muerte como límite, la experiencia de la finitud constituyen uno de los últimos «lugares» visitados, explorados, ocupados por la poesía de Blanca Varela; desde ellos, a través de ellos, también se ha medido, sopesado la humana condición. Posicionándose desde la doble perspectiva de una pertenencia, de un estar en el mundo y de una distancia, a través de los diversos descentramientos, extrañamientos, la sujeto/hablante esboza un horizonte sobre todo ético, en el que se apunta a un conocimiento y a la búsqueda de una autenticidad ansiada pero inalcanzable. En ese afán, la lengua poética construye su centro imposible, habla con diversas voces, entre las cuales son fundamentales las del ángel y el animal.

\section{Bibliografía}

Bataille Georges, L'expérience intérieure, Paris, Gallimard, 1954, 189 p.

Blanchot Maurice, La part du feu, Paris, Gallimard, 1949, 331 p.

— "Rilke ou l'expérience de la mort ", L'espace littéraire, Paris, Gallimard, 1955, $379 \mathrm{p}$.

Derrida Jacques, L'animal que donc je suis, Paris, Éditions Galilée, 2006, 219 p.

Forgues Roland, Palabra Viva: las poetas se desnudan, Lima, El Quijote, 1991, p. 7790.

Heidegger Martin, Chemins qui ne mènent nulle part, Paris, Gallimard, 1962, 461 p.

Kristal Efraín, «Entrevista con Blanca Varela», Mester Vol. XXIV, n 2, 1995, p. 133150 .

Lacoue-Labarthe Philippe, La poésie comme expérience, Paris, Christian Bourgois, 1986, $167 \mathrm{p}$.

O’Hara Edgar, «El recuerdo del recuerdo-conversación con Blanca Varela», Revista Peruana de Cultura 2, 1984, p. 11-29.

Paz Octavio, El arco y la lira, México, Fondo de Cultura Económica, 1956, 305 p.

Rilke Rainer Maria, Elegías de Duino, Lima, Pontificia Universidad Católica del Perú, 1997,87 p.

Rodríguez Monegal Emir, El viajero inmóvil, Buenos Aires, Editorial Losada, 1966, 348 p.

Savater Fernando, La vida eterna, Barcelona, Ariel, 2007, 261 p. 
Suárez Modesta, Espacio pictórico y espacio poético en la obra de Blanca Varela, Madrid, Editorial Verbum, 2003, 244 p.

Thélot Jérôme, La poésie précaire, Paris, Presses Universitaires de France, 1997, 150 p. Unamuno Miguel de, Del sentimiento trágico de la vida, Madrid, Espasa-Calpe, 1913, $321 \mathrm{p}$.

Valcárcel Rosina, «Blanca Varela: "Esto es lo que me tocado vivir"», La casa de Cartón de Oxy 10, 1997, p. 2-15.

Valente José Ángel, La experiencia abisal. Barcelona, Galaxia Gutenberg - Círculo de lectores, 2004, $234 \mathrm{p}$.

Varela Blanca, Donde todo termina abre las alas, Poesía reunida (1949-2000), Barcelona, Galaxia Gutenberg - Círculo de Lectores, 2001, 285 p.

— «Antes de escribir estas líneas.», Cuadernos Hispanoamericanos 417, 1985, p. 8486.

Zambrano María, El hombre y lo divino, México, Fondo de Cultura Económica, 1973, $412 \mathrm{p}$.

- Los lugares de la poesía, Madrid, Editorial Trotta, 2007, 292 p. 